()

\title{
Needle track seeding after radiofrequency ablation for hepatocellular carcinoma: prevalence, impact, and management challenge
}

This article was published in the following Dove Press journal:

Journal of Hepatocellular Carcinoma

20 January 2017

Number of times this article has been viewed

\author{
Giampiero Francica \\ Interventional Ultrasound Unit, \\ Department of Radiology, Pineta \\ Grande Hospital, Castel Volturno, Italy
}

\begin{abstract}
Neoplastic seeding may arise after radiofrequency ablation (RFA) for hepatocellular carcinoma (HCC). A low risk of seeding after RFA (0-1.1\%) has been reported, which may rise up to $2.5 \%$ if ablation followed diagnostic biopsy. Needle track seeding presents with one or multiple rounded nodules along the needle track located within the peritoneum, along the abdominal muscles, which were penetrated by the needle, pleural surface, or in the subcutaneous and cutaneous tissues. The most widely used method for the assessment of seeding nodules is ultrasound (US), which usually displays hypoechoic nodules with intralesional vascularization. Fine needle aspiration biopsy of the nodule suspicious for malignant implant is mandatory to confirm the diagnosis and plan therapy. Wide surgical excision is the treatment of choice for neoplastic seeding. Thanks to early diagnosis and prompt treatment, development of needle track seeding is not likely to affect the long-term survival of patients.
\end{abstract}

Keywords: ablation, biopsy, liver, seeding, HCC

\section{Introduction}

Incidence of $\mathrm{HCC}$ is growing in most countries. ${ }^{1}$ In contrast to the most common cancer sites (eg, prostate, breast, and colon) showing successful reductions in the occurrence and deaths, liver cancer, of which HCC represents $80 \%$, shows unfavorable trends; incidence and death rates are increasing at the highest rate of all cancer sites among both men and women. ${ }^{2}$

Infection with hepatitis $\mathrm{B}$ and/or $\mathrm{C}$ virus represents the main risk factor for the development of $\mathrm{HCC}$, contributing to $>60 \%$ of $\mathrm{HCC}$ cases. ${ }^{3}$ Other important risk factors for liver cancer include excessive alcohol consumption, nonalcoholic fatty liver disease, obesity, type 2 diabetes mellitus, and rare metabolic disorders. ${ }^{4,5}$

$\mathrm{HCC}$ is among the current leading causes of mortality of patients with cirrhosis, the group of patients with the utmost risk of developing HCC. ${ }^{6}$ Screening of cirrhotic patients using US with or without alfaphetoprotein determination increases the chance of detecting liver cancer at an early stage when it is more amenable to therapy, ${ }^{5,7}$ including percutaneous treatments (ethanol injection, radiofrequency, and microwaves) as curative therapeutic options. ${ }^{8,9}$

Among ablative therapies, RFA ranks first as diffusion, availability, and physicians' confidence in its therapeutic effectiveness. ${ }^{10,11}$ Recent meta-analyses ${ }^{12,13}$ have suggested that RFA achieved better survival and lower local tumor progression rates than ethanol injection. Moreover, recently published articles ${ }^{14-17}$ have shown that RFA can be offered to patients with HCC nodules up to $2 \mathrm{~cm}$ instead of surgical resection,
Correspondence: Giampiero Francica Interventional Ultrasound Unit, Pineta Grande Hospital, SS Domitiana Km 30,00, Castel Volturno (CE) 8I030, Italy Tel +3908238541601

Email giampierofrancica@gmail.com 
since overall survival and local control of the disease are the same in both the procedures.

Another factor accounting for worldwide spread of RFA is the good safety profile owing to low mortality and major complication rates. ${ }^{18,19}$ However, one of the most feared complications is malignant seeding, ie, development of neoplastic nodules along the needle path, since this is regarded as extrahepatic spread of the disease, thus heralding unfavorable prognosis.

\section{Definition}

Percutaneous insertion of a needle into a malignant lesion can entail releasing neoplastic cells along the needle track, so that a metastatic tumor may grow from a few months to several years (in the literature, the range is 6-46 months) after ablation.

Needle track seeding invariably presents with one or multiple rounded nodules along the needle track located within the peritoneum, along the abdominal muscles, which were penetrated by the needle, pleural surface, or in the subcutaneous and cutaneous tissues.

\section{Imaging}

At US seeding, implants present as hypoechoic nodules (Figures 1 and 2), with intralesional vascularization that can be demonstrated by color Doppler, contrast-enhanced US, $\mathrm{CT}$, and MRI, overlapping behavior of intrahepatic tumor. Hypovascular nodules represent a caveat; in these cases, inflammatory processes should be considered. ${ }^{20}$ Patient written informed consent including usage of data and images were obtained from the patients for this review.

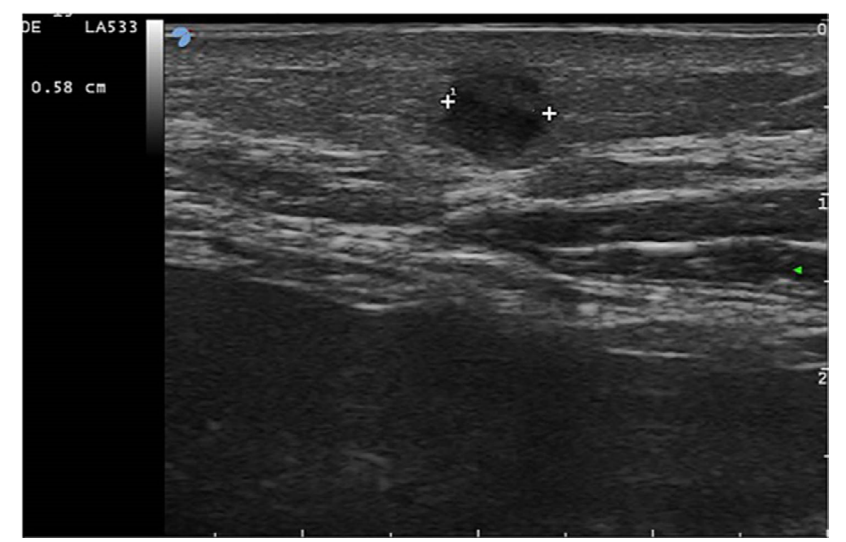

Figure I Three months after RF ablation of a $2 \mathrm{~cm} \mathrm{HCC}$ nodule in the left lobe, the follow-up US shows a $6 \mathrm{~mm}$ hypoechoic nodule (between markers) in the subcutaneous layer of the abdominal wall at the point of the previous insertion of the electrode needle.

Note: Malignant HCC cells were shown at FNB.

Abbreviations: RF, radiofrequency; US, ultrasound; HCC, hepatocellular carcinoma; FNB, fine needle biopsy.

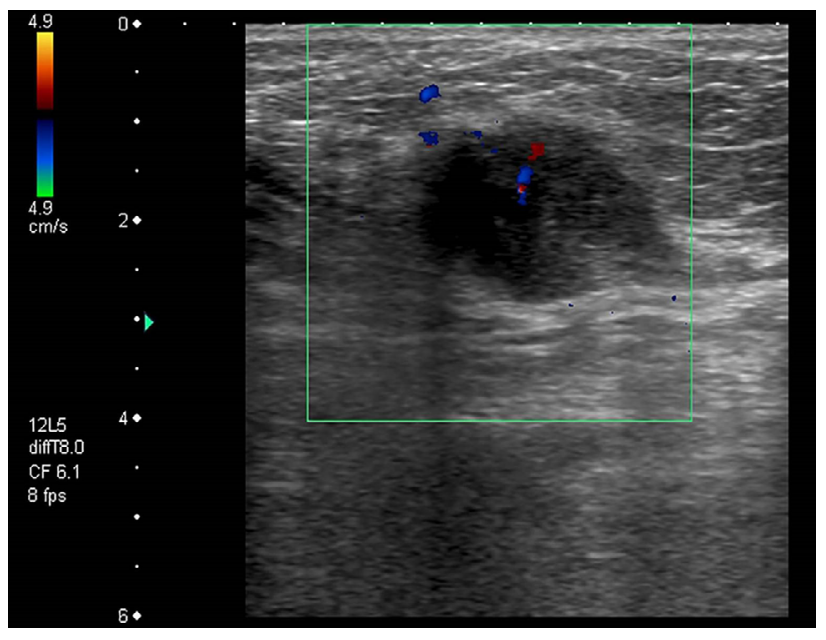

Figure 2 Subcutaneous $\mathrm{HCC}$ seeding shows an intralesional vascular pole at color Doppler examination.

Abbreviation: HCC, hepatocellular carcinoma.

In case of large implants infiltrating different structures of the abdominal or chest wall, CT and MRI examinations show the extent of the lesion more accurately than does US, which may not image the entire lesion. In the author's opinion, fine needle biopsy (FNB) of the nodule suspicious for malignant implant is mandatory to confirm the diagnosis and plan therapy.

Since the most frequent site of neoplastic implant is the musculocutaneous plane, the area including the needle track of previous biopsy or percutaneous ablative treatment should always be scanned with higher frequency probes (5.0-7.5 MHz) that also have higher resolution and higher sensitivity for color Doppler signals. ${ }^{20}$

\section{Pathogenesis}

Several associated risk factors have been identified for neoplastic seeding following RFA for HCC, notably subcapsular tumor location, ${ }^{21,22}$ tumor characteristics, such as poor differentiation grade ${ }^{22}$ and intrinsic metastatic property, ${ }^{23}$ multiple RFA sessions, ${ }^{22}$ history of previous biopsy, ${ }^{22,24}$ and patient's immunodepression.

Several mechanisms have been proposed to explain the occurrence of seeding after percutaneous ablative procedures: tumor cells may adhere to an electrode during its retraction; tumor cells may also be carried into the track with a little bleeding; furthermore, increase in intratumoral pressure, which is frequently encountered during RFA, may force cells into the track. ${ }^{18,25}$

According to Snoeren et al, ${ }^{26}$ the incidence of viable cells was $17.9 \%$ and the incidence of morphologically intact tumor cells was $28.6 \%$ when track ablation was not performed. On the contrary, no viable or morphologically intact tumor cells 
could be demonstrated when track ablation was applied during RFA procedure.

\section{Frequency}

Initially, the report from the Barcelona group of a seeding rate as high as $12.5 \%$ in a small series of HCC treated with RFA raised serious concern about the safety of percutaneous thermal ablation. ${ }^{21}$ However, it soon became clear that major factors explaining these results were incorrect withdrawal technique (no track ablation had been carried out) and previous diagnostic biopsy. A large survey from Livraghi et $\mathrm{al}^{24}$ reported a low rate of tumor seeding $(0.9 \%)$ in 1314 patients and showed that only previous biopsy was significantly associated with tumor seeding. The low risk of seeding after RFA (0-1.1\%) has been confirmed in other studies. ${ }^{27-29}$ The systematic review by Stigliano et $\mathrm{al}^{30}$ confirmed that biopsy prior to RFA increases the risk of seeding since the mean risk for seeding after RFA alone was $1.73 \%$ (range $0-5.56 \%$ ) rising up to $2.5 \%$ (range $0-12.5 \%$ ) if ablation followed diagnostic biopsy.

Although superficial location of the tumor ${ }^{21,22}$ has been advocated as a predisposing factor, a recent series showed that direct subcapsular HCC treated by direct access with radiofrequency $(\mathrm{RF})$ or microwave (MW) did not increase seeding rate. ${ }^{31}$ Indeed, the only patient with needle track seeding in this series had a previous diagnostic biopsy.

\section{Treatment}

Wide surgical excision is considered as the first-line therapy, provided fascia-to-fascia closure under acceptable tension is feasible. ${ }^{32}$ The importance of a wide excision is underlined by the possibility of relapsing seeding after incomplete surgical removal of a neoplastic implant. ${ }^{33}$

Other treatments have been proposed alone, such as TACE,${ }^{34}$ MWA and HIFU,${ }^{25}$ and in combination with surgery, such as RFA and PEI. ${ }^{24}$

As a rule, the presence of seeding is considered as a contraindication to OLT, but living donor liver transplantation for HCC with full-thickness abdominal wall resection bearing the tumor implant has been recently reported. ${ }^{35}$

\section{Clinical impact}

In the meta-analysis of Silva et al, ${ }^{36}$ the seeding event had no impact on the patient's survival when the lesion was treated successfully by resection and local ablation. Similarly, in the study of Imamura et al, ${ }^{37}$ the cumulative survival rates in HCC patients with neoplastic seeding were $81 \%$ at 1 year and $45 \%$ at 2 years.
Taking into consideration the relatively low incidence of needle track seeding, the risk of neoplastic implant after thermal ablation could be considered as an acceptable clinical risk.

\section{Prevention}

Although surgical sealant infusion ${ }^{38}$ has been advocated as a procedure preventing seeding, no robust data exist in the literature. Theoretically, the following two other methods could reduce neoplastic seeding: 1) the coaxial technique as already suggested for biopsy; ${ }^{39}$ however, needle track implant after biopsy with such a method has been recently reported, ${ }^{40}$ and 2) RFA under laparoscopy as suggested by Santambrogio et al. ${ }^{41}$ RF electrodes can be passed through larger laparoscopic sheaths, so avoiding contact of the therapeutic needle with the abdominal wall. However, in this laparoscopic series, seeding occurred after treatment of a large lesion, which required the use of a cluster needle. In addition, it should be underlined that laparoscopic approach is not used as frequently as the percutaneous approach and seems to be limited to those cases when the percutaneous approach to the lesion is deemed very difficult or impossible.

Generally speaking, the biopsy should be avoided especially when a therapeutic option is under consideration for HCC (percutaneous treatment with RF or MW and liver transplantation), relying on good quality cross-sectional imaging. If biopsy is considered mandatory, the number of needle passes should be kept at minimum.

For percutaneous hyperthermic therapeutic procedures, correct needle withdrawal by burning the needle track plays a major role in preventing seeding, even in subcapsular nodules and especially when multiple needle insertions are needed to treat large tumors so as to obtain overlapping ablations or to reposition the needle in a small tumor. In this regard, inexperienced operators should avoid multiple attempts to position the electrode without carrying out track ablation at each withdrawal.

\section{Conclusion}

Although needle track seeding after RFA for HCC is traditionally regarded as an ominous complication, its real incidence is acceptably low and can be minimized by reducing biopsy prior to therapeutic interventions and by carrying out needle track ablation after successful thermal ablation of HCC nodules. In addition, thanks to early diagnosis and prompt treatment, development of needle track seeding is not likely to affect the long-term survival of patients. 


\section{Abbreviations}

FNB, fine needle biopsy; HCC, hepatocellular carcinoma; RFA, radiofrequency ablation; MWA, microwave ablation; PEI, percutaneous ethanol injection; US, ultrasound; MRI, magnetic resonance imaging; CT, computed tomography; HIFU, high-intensity focused ultrasound; TACE, transcatheter arterial chemoembolization; OLT, orthotopic liver transplant.

\section{Disclosure}

The author reports no conflicts of interest in this work.

\section{References}

1. Ferlay J, Soerjomataram I, Dikshit R, et al. Cancer incidence and mortality worldwide: sources, methods and major patterns in GLOBOCAN 2012 [serial online]. Int J Cancer. 2015;136:E359-E386.

2. Ryerson AB, Eheman CR, Altekruse SF, et al. Annual report to the nation on the status of cancer, 1975-2012, featuring the increasing incidence of liver cancer. Cancer. 2016;122(9):1312-1337.

3. de Martel C, Maucort-Boulch D, Plummer M, Franceschi S. Worldwide relative contribution of hepatitis $\mathrm{B}$ and $\mathrm{C}$ viruses in hepatocellular carcinoma. Hepatology. 2015;62(4):1190-1200.

4. Welzel TM, Graubard BI, Quraishi S, et al. Population-attributable fractions of risk factors for hepatocellular carcinoma in the United States. Am J Gastroenterol. 2013;108(8):1314-1321.

5. Ballestri S, Romagnoli D, Nascimbeni F, Francica G, Lonardo A. Role of ultrasound in the diagnosis and treatment of nonalcoholic fatty liver disease and its complications. Expert Rev Gastroenterol Hepatol. 2015;9:603-627.

6. Njei B, Rotman Y, Ditah I, Lim JK. Emerging trends in hepatocellular carcinoma incidence and mortality. Hepatology. 2015;61:191-199.

7. Singal A, Volk ML, Waljee A, et al. Meta-analysis: surveillance with ultrasound for early-stage hepatocellular carcinoma in patients with cirrhosis. Aliment Pharmacol Ther. 2009;30(1):37-47.

8. Bruix J, Sherman M. Management of hepatocellular carcinoma: an update. Hepatology. 2011;53:1020-1022.

9. European Association for the Study of the Liver; European Organisation for Research and Treatment of Cancer. EASL-EORTC clinical practice guidelines: management of hepatocellular carcinoma. J Hepatol. 2012;56:908-943.

10. Gervais DA, Arellano RS. Percutaneous tumor ablation for hepatocellular carcinoma. AJR Am J Roentgenol. 2011;197(4):789-794.

11. Lencioni R, Crocetti L. Local-regional treatment of hepatocellular carcinoma. Radiology. 2012;262(1):43-58.

12. Cho YK, Kim JK, Kim MY, Rhim H, Han JK. Systematic review of randomized trials for hepatocellular carcinoma treated with percutaneous ablation therapies. Hepatology. 2009;49:453-459.

13. Germani G, Pleguezuelo M, Gurusamy K, MeyerT, Isgro G, Burroughs AK. Clinical outcomes of radiofrequency ablation, percutaneous alcohol and acetic acid injection for hepatocelullar carcinoma: a meta-analysis. J Hepatol. 2010;52(3):380-388.

14. Livraghi T, Meloni F, Di Stasi M, et al. Sustained complete response and complications rates after radiofrequency ablation of very early hepatocellular carcinoma in cirrhosis: is resection still the treatment of choice? Hepatology. 2008;47(1):82-89.

15. N'Kontchou G, Mahamoudi A, Aout M, et al. Radiofrequency ablation of hepatocellular carcinoma: long-term results and prognostic factors in 235 Western patients with cirrhosis. Hepatology. 2009;50(5):1475-1483.

16. Chen MS, Li JQ, Zheng Y, et al. A prospective randomized trial comparing percutaneous local ablative therapy and partial hepatectomy for small hepatocellular carcinoma. Ann Surg. 2006;243(3):321-328.

17. Feng K, Yan J, Li X, et al. A randomized controlled trial of radiofrequency ablation and surgical resection in the treatment of small hepatocellular carcinoma. J Hepatol. 2012;57(4):794-802.
18. Mulier S, Mulier P, Ni Y, et al. Complications of radiofrequency coagulation of liver tumours. Br J Surg. 2002;89:1206-1222.

19. Livraghi T, Solbiati L, Meloni MF, Gazelle GS, Halpern EF, Goldberg SN. Treatment of focal liver tumors with percutaneous radio-frequency ablation: complications encountered in a multicenter study. Radiology. 2003;226(1):441-451.

20. Tarantino L, Francica G, Esposito F, et al. Seeding from hepatocellular carcinoma after percutaneous ablation: color Doppler ultrasound findings. Abdom Imaging. 2006;31(1):69-77.

21. Llovet JM, Vilana R, Brú C, et al; Barcelona Clínic Liver Cancer (BCLC) Group. Increased risk of tumor seeding after percutaneous radiofrequency ablation for single hepatocellular carcinoma. Hepatology. 2001;33(5):1124-1129.

22. Jaskolka JD, Asch MR, Kachura JR, et al. Needle tract seeding after radiofrequency ablation of hepatic tumors. J Vasc Interv Radiol. 2005; 16(4):485-491.

23. Malik STA, Naylor MS, East N, et al. Cells secreting tumor necrosis factor show enhanced metastasis in nude mice. Eur J Cancer. 1990; 26:1031-1034.

24. Livraghi T, Lazzaroni S, Meloni F, Solbiati L. Risk of tumour seeding after percutaneous radiofrequency ablation for hepatocellular carcinoma. Br J Surg. 2005;92(7):856-858.

25. Yu J, Liang P, Yu XL, Cheng ZG, Han ZY, Dong BW. Needle track seeding after percutaneous microwave ablation of malignant liver tumors under ultrasound guidance: analysis of 14-year experience with 1462 patients at a single center. Eur J Radiol. 2012;81(10):2495-2499.

26. Snoeren N, Jansen MC, Rijken AM, et al. Assessment of viable tumour tissue attached to needle applicators after local ablation of liver tumours. Dig Surg. 2009;26(1):56-62.

27. Poon RT, Ng KK, Lam CM, Ai V, Yuen J, Fan ST. Radiofrequency ablation for subcapsular hepatocellular carcinoma. Ann Surg Oncol. 2004;11(3):281-289.

28. Latteri F, Sandonato L, Di Marco V, et al. Seeding after radiofrequency ablation of hepatocellular carcinoma in patients with cirrhosis: a prospective study. Dig Liver Dis. 2008;40(8):684-689.

29. Francica G, Saviano A, De Sio I, et al. Long-term effectiveness of radiofrequency ablation for solitary small hepatocellular carcinoma: a retrospective analysis of 363 patients. Dig Liver Dis. 2013;45(4): 336-341.

30. Stigliano R, Marelli L, Yu D, Davies N, Patch D, Burroughs AK. Seeding following percutaneous diagnostic and therapeutic approaches for hepatocellular carcinoma. What is the risk and the outcome? Seeding risk for percutaneous approach of HCC. Cancer Treat Rev. 2007;33: 437-447.

31. Francica G, Meloni MF, de Sio I, et al. Radiofrequency and microwave ablation of subcapsular hepatocellular carcinoma accessed by direct puncture: safety and efficacy. Eur J Radiol. 2016;85(4):739-743.

32. Ahn DW, Shim JH, Yoon JH, et al. Treatment and clinical outcome of needle-track seeding from hepatocellular carcinoma. Korean J Hepatol. 2011;17(2):106-112.

33. Francica G, Marone G, D'Angelo V, et al. Relapsing neoplastic seeding after percutaneous ethanol injection for hepatocellular carcinoma. Clinical and ultrasonographic findings in a cirrhotic patient. Eur $J$ Ultrasound. 1997;6:185-189.

34. Shibata T, Shibata T, Maetani Y, Kubo T, Nishida N, Itoh K. Transcatheter arterial embolization for tumor seeding in the chest wall after radiofrequency ablation for hepatocellular carcinoma. Cardiovasc Intervent Radiol. 2006;29(3):479-481.

35. Yang HR, Thorat A, Gesakis K, et al. Living donor liver transplantation with abdominal wall reconstruction for hepatocellular carcinoma with needle track seeding. World J Transplant. 2015;5(4):360-365.

36. Silva MA, Hegab B, Hyde C, Guo B, Buckels JA, Mirza DF. Needle track seeding following biopsy of liver lesions in the diagnosis of hepatocellular cancer: a systematic review and meta-analysis. Gut. 2008;57(11):1592-1596.

37. Imamura J, Tateishi R, Shiina S, et al. Neoplastic seeding after radiofrequency ablation for hepatocellular carcinoma. Am J Gastroenterol. 2008;103(12):3057-3062. 
38. Izzo F, Palaia R, Albino V, et al. Hepatocellular carcinoma and liver metastases: clinical data on a new dual-lumen catheter kit for surgical sealant infusion to prevent perihepatic bleeding and dissemination of cancer cells following biopsy and loco-regional treatments. Infect Agent Cancer. 2015;10(10):11.

39. Azoulay D, Johann M, Raccuia JS, Castaing D, Bismuth H. "Protected" double needle biopsy technique for hepatic tumors. J Am Coll Surg. 1996;183:160-163.
40. Tchatalbachev VV, Kirkpatrick DL, Deiter J, Duff DJ, Travis MD Seeding of the rectus sheath with hepatocellular carcinoma after image guided percutaneous liver biopsy using coaxial biopsy needle system. J Radiol Case Rep. 2015;9:18-25.

41. Santambrogio R, Opocher E, Costa M, Cappellani A, Montorsi M. Survival and intra-hepatic recurrences after laparoscopic radiofrequency of hepatocellular carcinoma in patients with liver cirrhosis. J Surg Oncol. 2005;89(4):218-226.

\section{Publish your work in this journal}

The Journal of Hepatocellular Carcinoma is an international, peerreviewed, open access journal that offers a platform for the dissemination and study of clinical, translational and basic research findings in this rapidly developing field. Development in areas including, but not limited to, epidemiology, vaccination, hepatitis therapy, pathology and molecular tumor classification and prognostication are all considered for publication. The manuscript management system is completely online and includes a very quick and fair peer-review system, which is all easy to use. Visit http://www.dovepress.com/testimonials.php to read real quotes from published authors.

Submit your manuscript here: https:/www.dovepress.com/journal-of-hepatocellular-carcinoma-journal 